\title{
Weather Uncertainty and Efficacy of Fumigation in Tomato Production
}

\author{
Feng Wu ${ }^{1, *}$, Berdikul Qushim ${ }^{2}$, Zhengfei Guan ${ }^{1}$, Nathan S. Boyd ${ }^{1}$, Gary E. Vallad ${ }^{1}$, \\ Andrew MacRae ${ }^{1}$ and Tyler Jacoby ${ }^{1}$ \\ 1 Gulf Coast Research and Education Center, University of Florida, 14625 CR 672, Wimauma, FL 33598, USA; \\ guanz@ufl.edu (Z.G.); nsboyd@ufl.edu (N.S.B.); gvallad@ufl.edu (G.E.V.); \\ andrew.macrae@corteva.com (A.M.); newgenag@gmail.com (T.J.) \\ 2 Office of Institutional Effectiveness, Southern University and A\&M College, Augustus C. Blanks Hall, Baton \\ Rouge, LA 70813, USA; berdikul_qushim@subr.edu \\ * Correspondence: fengwu@ufl.edu
}

Received: 24 October 2019; Accepted: 22 December 2019; Published: 25 December 2019

check for updates

\begin{abstract}
This study quantifies the effect of weather factors on fumigation efficacy in terms of weed control, tomato yield, and the overall economic performance of fumigants. High soil temperature was found to reduce the efficacy of all fumigants against nutsedge, while rainfall only reduced the efficacy of a limited number of fumigants. The fumigants' economic performance over a range of weather conditions was further simulated to identify the fumigant that is most effective under diverse weather conditions. The results show that although 1,3-D:Pic:Kpam outperforms methyl bromide over the experiment period, methyl bromide is still the best treatment when accounting for the impact of weather variability. The study illustrates the sensitivity of fumigant efficacy to weather conditions and the importance of achieving consistent and sustainable efficacy. The regression model and the expected utility model, along with the simulation techniques, form a useful tool that can be applied across regions or crops.
\end{abstract}

Keywords: fumigation efficacy; methyl bromide alternatives; Monte Carlo simulation; tomato production; weather uncertainty

\section{Introduction}

Fresh tomatoes (Lycopersicon esculentum Mill.) are an important crop in the U.S. fruit and vegetable industry, with a national farm gate value of $\$ 0.8$ billion in 2018. U.S. growers historically relied on methyl bromide (MBr) to control and regulate soil-borne pests including fungi, nematodes, insects, mites, rodents, bacteria and weeds. However, the MBr phase-out resulted in a broad technological shock for the tomato industry. The USDA has supported research to develop MBr alternatives, however, no alternative fumigant with the same broad-spectrum efficacy and consistency as $\mathrm{MBr}$ has been identified. Many alternative fumigants have been registered that can be used in combinations, or in sequence [1-5], but it is generally acknowledged that these alternatives tend to provide inconsistent weed control [6]. For instance, Gilreath and Santos [3] found that combination of $\mathrm{MBr}$ and chloropicrin (Pic) controlled purple nutsedge more effectively than 1,3-dichloropropene (1,3-D): Pic in combination with pebulate in the 1997/1998 tomato season, while another experiment conducted by Gilreath et al. [5] in 2000/2001 showed that there was no significant performance difference between them. Weed control with alternative fumigants has been variable with reports of both acceptable and poor control compared to $\mathrm{MBr}$ [7]. Alternatives that have acceptable efficacy under favorable weather may fail in other years when the weather is less favorable. 
Previous studies have suggested that variability in fumigation efficacy is due, at least in part, to soil conditions. Fumigants function well, only in an environment where the soil concentration and exposure duration are adequate for pest termination. However, soil moisture and temperature can respond rapidly to changes in the atmosphere. In some cases, the concentration is reduced and the duration is shortened, causing limited efficacy [1]. Therefore, the rate of chemical conversion, distance moved, and the rate of movement are affected by rainfall or irrigation and temperature. To identify the most efficacious fumigant alternative, it is necessary to examine fumigation efficacy over multiple years with varying rainfall and temperature. Although it is well documented that fumigation efficacy is sensitive to weather conditions, no study has systematically shown how weather conditions affect efficacy. The current study is based on data from a four-year trial in Florida and identifies the effect of weather conditions such as soil temperature and rainfall on fumigant efficacy including $\mathrm{MBr}$, the current industry standard, and other promising $\mathrm{MBr}$ alternatives.

The economic performance of fumigants under variable weather conditions is further evaluated in the study. An economic evaluation of fumigants based on limited-year trials is not reliable because fumigation efficacy varies over time. Several studies have examined economic effects of fumigant alternatives on vegetable production in the U.S. using partial budgeting analysis [8,9] or stochastic dominance analysis $[10,11]$. The recommended fumigant alternatives in these studies are not necessarily economically sustainable or viable given that experiments were only conducted under fixed or limited variation in weather conditions. Results on economic performance are more reliable when taking into account sufficient variation in weather conditions.

The objective of this study is to identify optimal fumigants, taking into account weather impact and variability. To achieve the objective, empirical models were developed to quantify the effects of weather conditions on weed control and tomato yield. Based on the estimated effect and yield response, tomato yield and growers' expected utility under diverse weather scenarios was calculated with a simulation approach to identify optimal fumigants. The information generated from this analysis illustrated the difference between accounting for weather variation and not accounting for it. The findings from the study will provide an important, long-term perspective for horticulturalists, pest management experts, and growers.

\section{Materials and Methods}

\subsection{Experiment Design}

Tomato field trials were conducted at the University of Florida Gulf Coast Research and Education Center in Balm, Florida, U.S., over a four-year period from the fall of 2008 through to the fall of 2011. The soil type at the experimental site was Myakka fine sand (Siliceous Hyperthermic Oxyaquic Alorthod) with about $1 \%$ organic matter, low fertility, rapid infiltration, and high water tables. Fumigant treatments included: a non-fumigated control; MBr:Pic 67:33 at $196 \mathrm{~kg} \cdot \mathrm{ha}^{-1}$; dimethyl disulfide plus Pic (DMDS:Pic 79:21) at 561 L·ha ${ }^{-1} ; 1,3-\mathrm{D}$ at $112 \mathrm{~L} \cdot \mathrm{ha}^{-1}$ plus Pic at $168 \mathrm{~kg} \cdot \mathrm{ha}^{-1}$ (1,3-D:Pic), collectively referred to as the two-way system which is also the current industry standard; and the two-way system followed by metam potassium at $561{\mathrm{~L} \cdot \mathrm{ha}^{-1}}^{-1} \mathrm{Kpam}$ ) (1,3-D:Pic:Kpam), collectively referred to as the three-way system. Treatments were arranged in a randomized complete block design with fumigation as the main plot and herbicide as a non-randomized subplot effect in four field sites. Treatments were assigned to three-bed main plots and replicated three times, while each main plot consisted of herbicide and non-herbicide sub-plots. Each main plot was $92 \mathrm{~m}$ long and sub-plots were $23 \mathrm{~m}$ long. Beds were spaced $1.5 \mathrm{~m}$ apart (bed center to bed center) with a $75 \mathrm{~cm}$ bed top and $23 \mathrm{~cm}$ bed height. The trial site and plot location were maintained throughout the length of the study to determine the effect of treatments over four years. The 1,3-D was applied 30-35 cm below the bed top using a Yetter coulter rig. A nitrogen propelled single row fumigation rig (Kennco Manufacturing, Ruskin, FL, USA) was used to inject the remaining fumigants (except for the Kpam) $20 \mathrm{~cm}$ deep into the bed. These applications occurred on 12 August 2008, 28 July 2009, 5 August 2010, and 17 August 2011, respectively. 
Beds were then sealed using a single row bed press after applications. Kpam was injected into the beds using double drip tapes two weeks after laying the plastic. The injection lasted for three hours with $15 \mathrm{~min}$ of irrigation prior to injection and $30 \mathrm{~min}$ of irrigation following injection to flush the system of fumigant. Herbicides were applied to soil surfaces with a tractor mounted sprayer and nozzles calibrated to deliver $280 \mathrm{~L} \cdot \mathrm{ha}^{-1}$.

The experimental field was prepared using conventional tillage, and beds were shaped using a 3-row bed press rig. Two drip tapes were placed $30 \mathrm{~cm}$ apart and buried $2.5 \mathrm{~cm}$ deep in each bed. All beds were covered with virtually impermeable film. Tomato plants were transplanted about 40 days after fumigation when fumigant concentration in the bed was safe. Holes were punched through the film about $30 \mathrm{~min}$ before hand transplanting. Tomatoes were planted $45 \mathrm{~cm}$ apart and $10 \mathrm{~cm}$ deep on 23 September 2008, 17 September 2009, 15 September 2010, and 21 September 2011, which corresponds to $42,51,41$, and 35 days after fumigation, respectively. Throughout each growing season, the crop was managed using University of Florida recommended production practices [6]. Weed populations that escaped the control of the fumigants and/or herbicides were assessed a minimum of two times each cropping season. Within each plot, the number of purple and yellow nutsedge (Cyperus spp.) seedlings that emerged through the plastic and the number of annual grasses that emerged from the planting holes were counted. The tomato crop was harvested in December.

\subsection{Effect of Weather Factors}

The efficacy of soil fumigation is greatly affected by soil and environmental conditions during and immediately following fumigation until transplanting. To effectively control weeds, fumigants must penetrate and diffuse into soil pores and be retained in the gas form for a period of time. Many weather factors positively or negatively affect the activity of fumigants. This research tested the effect of soil temperature and rainfall on fumigant efficacy on weeds. Since a significant fraction of subplots had zero weeds, a Tobit model was adopted to estimate the effect of two factors on controlling nutsedge and grass [12]. The Tobit model is appropriate when the modeled variable is censored below or above a certain value and may have multiple observations at the censoring limit [13]. In this case, the weed number has a lower bound of zero with a number of plots of zero weeds. The censored Tobit model of a certain weed $W_{k}$ is:

$$
\begin{gathered}
W_{k}=\max \left(0, y_{k}\right), \\
y_{k}=c_{k}+\sum_{i=1}^{5} \beta_{k i} X_{i}+\sum_{i=1}^{5} \sum_{j=1}^{2} \theta_{k i j} X_{i} Z_{j}+u_{k}
\end{gathered}
$$

where $W_{k}$ is the weed variable (nutsedge or grass for $k=1,2$ ), taking values $y$ if $y$ is positive and zero otherwise; $c$ is the constant term; $X$ includes five dummy variables representing four fumigants of MBr:Pic, DMDS:Pic, 1,3-D:Pic, 1,3-D:Pic:Kpam (the non-fumigated control is the default and is omitted), and herbicide ( $\left.X_{5}\right) ; X Z$ is the interaction terms of dummy variables with two weather factors in $Z ; \beta, \theta$ are vectors of unknown coefficients to be estimated; and $u_{k}$ is an independently distributed error term assumed to be normal with zero mean and variance $\sigma_{k}^{2}$. Soil temperature after fumigation (TAF) $\left(Z_{1}\right)$ is the average temperature during the plant-back interval, namely, from fumigation until transplanting, while rainfall after fumigation (RAF) $\left(Z_{2}\right)$ is the total precipitation during the same period. Table 1 shows the values of these two variables over the experiment period.

After modeling the treatment and weather effects on weeds, tomato yield was further modeled as a function of weather conditions (temperature and rainfall) and weed and non-weed pressure:

$$
Y=\gamma_{0}+\sum_{i=1}^{4} \gamma_{i} X_{i}+\gamma_{5} T A T+\gamma_{6} R A T+\sum_{k=1}^{2} \gamma_{k+6} W_{k}+\varepsilon
$$

where $Y$ is the tomato yield; $W_{k}$ is weed; $X_{i}$ is dummy variables of fumigants, capturing additional, non-weed pest pressure associated with fumigant use that affects yield, such as nematodes; TAT is 
soil temperature after transplanting, measured as average soil temperature over the growing period from the middle of September to the beginning of December, while $R A T$ is rainfall after transplanting, measured as the total precipitation over the same period (Table 1 ); $\gamma$ is a vector of unknown coefficients, and $\varepsilon$ is the error term.

Table 1. Weather conditions during the experiment period.

\begin{tabular}{ccccc}
\hline Variables & $\mathbf{2 0 0 8}$ & $\mathbf{2 0 0 9}$ & $\mathbf{2 0 1 0}$ & $\mathbf{2 0 1 1}$ \\
\hline TAF & 81.239 & 79.627 & 81.624 & 81.849 \\
TAT & 72.284 & 74.772 & 71.926 & 73.597 \\
RAF & 3.365 & 9.009 & 10.977 & 6.475 \\
RAT & 4.765 & 5.627 & 2.247 & 6.544 \\
\hline
\end{tabular}

Note: TAF and TAT are average soil temperatures $\left({ }^{\circ} \mathrm{F}\right)$ after fumigation and transplanting, while RAF and RAT are total rainfalls (inch) after fumigation and transplanting, respectively.

The effects of fumigation treatments $X_{i}(i=1$ to 4$)$ and weather factor $Z_{j}(j=1,2)$ on fumigants' efficacy in tomato yield are further derived. Signs of $\beta$ and $\theta$ in Equation (1) determine the direction of change in weed population as the respective explanatory variables change. However, they do not directly give the marginal effects of the independent variables on the dependent variable. For dummy variables, the marginal effects are the difference when the respective dummy takes values 0 and 1 , respectively. Therefore, for any fumigant $X_{i}(i=1$ to 4$)$, its efficacy in controlling weed population is:

$$
\begin{gathered}
M W_{k i}=E\left(W_{k} \mid X_{i}=1\right)-E\left(W_{k} \mid X_{i}=0\right) \\
=\Phi\left(\frac{c_{k}+\beta_{k i}+\theta_{k i} Z}{\sigma_{k}}\right)\left(c_{k}+\beta_{k i}+\theta_{k i} Z\right)+\sigma_{k} \phi\left(\frac{c_{k}+\beta_{k i}+\theta_{k i} Z}{\sigma_{k}}\right)-\Phi\left(\frac{c_{k}}{\sigma_{k}}\right) c_{k}-\sigma_{k} \phi\left(\frac{c_{k}}{\sigma_{k}}\right)
\end{gathered}
$$

where $\phi(\cdot)$ and $\Phi(\cdot)$ are the density function and cumulative distribution of a standard normal variable. Subsequently, the effect of any weather factor $Z_{j}(j=1,2)$ on the efficacy of fumigant $X_{i}$ can be derived as:

$$
\frac{\partial M W_{k i}}{\partial Z_{j}}=\Phi\left(\frac{c_{k}+\beta_{k i}+\theta_{k i} Z}{\sigma_{k}}\right) \theta_{k i j}
$$

where $\Phi\left(\frac{c_{k}+\beta_{k i}+\theta_{k i} Z}{\sigma_{k}}\right)$ is the probability of observing a positive weed population for fumigant $X_{i}$, which is between zero and one. Therefore, the direction of the weather factors' effect on fumigant efficacy is determined by $\theta_{k i j}$, whereas the magnitude is less than $\theta_{k i j}$. The estimated marginal effect of fumigant $X_{i}(i=1$ to 4$)$ on tomato yield is:

$$
M Y_{i}=\gamma_{i}+\sum_{k=1}^{2} \gamma_{k+6} M W_{k i}
$$

The marginal yield effect is a combination of weed impact and non-weed impact associated with the fumigant. Then, the effect of weather factor $Z_{j}(j=1,2)$ on fumigants' efficacy in tomato yield is:

$$
\frac{\partial M Y_{i}}{\partial Z_{j}}=\sum_{k=1}^{2} \gamma_{k+6} \theta_{k i j} \Phi\left(\frac{c_{k}+\beta_{k i}+\theta_{k i} Z}{\sigma_{k}}\right)
$$

\section{Results}

\subsection{Weed Control and Tomato Yield}

To compare the means between fumigation treatments for weeds and yield, Tukey's adjusted means comparisons were used for all pairwise differences. During the four seasons, nutsedge density tended to be higher in the non-fumigated treatment (Table 2). 1,3-D:Pic, the industry standard, did not perform better than the non-fumigated in three of the four seasons, whereas 1,3-D:Pic:Kpam provided better control than the non-fumigated and was as effective as MBr:Pic in three of the four seasons. Additionally, DMDS:Pic and MBr:Pic worked equally well in three of the four seasons. Grass control 
was relatively more consistent. 1,3-D:Pic:Kpam was as effective as MBr:Pic and tended to provide the best grass control. Finally, all fumigants improved yield. Although 1,3-D:Pic:Kpam tended to be the highest yielding fumigant treatment, the yield difference among fumigant treatments was not always statistically significant. The data illustrate the season-to-season variability typically observed in fumigant trials [5].

Table 2. Weed shoots and tomato yields in plots treated with different fumigants.

\begin{tabular}{|c|c|c|c|c|c|}
\hline Treatment & 2008 & 2009 & 2010 & 2011 & Average \\
\hline \multicolumn{6}{|c|}{ Nutsedge Shoots (shoots $/ \mathrm{m}^{2}$ ) } \\
\hline Control & $0.234^{\mathrm{a}}$ & $4.281^{\mathrm{a}}$ & $11.808^{a}$ & $7.195^{a}$ & $5.880^{\mathrm{a}}$ \\
\hline MBr:Pic & $0.028^{\mathrm{a}, \mathrm{b}}$ & $0.021^{b}$ & $1.525^{b}$ & $1.433^{\mathrm{b}}$ & $0.752^{c}$ \\
\hline DMDS:Pic & $0.117^{\mathrm{a}}$ & $0.217^{b}$ & $2.551^{\mathrm{b}}$ & $5.584^{\mathrm{a}}$ & $2.117^{b, c}$ \\
\hline 1,3-D:Pic & $0.100^{\mathrm{a}}$ & $0.178^{b}$ & $7.489^{\mathrm{a}}$ & $5.247^{\mathrm{a}}$ & $3.254^{b}$ \\
\hline 1,3-D:Pic:Kpam & $0.004^{\mathrm{b}}$ & $0.013^{\mathrm{b}}$ & $1.009^{b}$ & $3.748^{\mathrm{a}}$ & $1.194^{\mathrm{c}}$ \\
\hline \multicolumn{6}{|c|}{ Grass Shoots (shoots $/ \mathrm{m}^{2}$ ) } \\
\hline Control & $0.305^{\mathrm{a}}$ & $0.847^{\mathrm{a}}$ & $0.158^{a}$ & & $0.437^{\mathrm{a}}$ \\
\hline MBr:Pic & $0.015^{\mathrm{b}}$ & $0.012^{b}$ & $0.013^{\mathrm{b}}$ & & $0.013^{c}$ \\
\hline DMDS:Pic & $0.322^{a}$ & $1.402^{\mathrm{a}}$ & $0.283^{\mathrm{a}}$ & & $0.669^{b}$ \\
\hline 1,3-D:Pic & $0.028^{b}$ & $0.314^{\mathrm{a}}$ & $0.087^{\mathrm{a}}$ & & $0.143^{c}$ \\
\hline 1,3-D:Pic:Kpam & $0.004^{b}$ & $0.012^{b}$ & $0.014^{\mathrm{b}}$ & & $0.010^{\mathrm{c}}$ \\
\hline \multicolumn{6}{|c|}{ Tomato Yields (Tons/ha) } \\
\hline Control & $26.103^{a}$ & $30.351^{a}$ & $22.904^{\mathrm{a}}$ & $21.229^{a}$ & $25.147^{\mathrm{a}}$ \\
\hline MBr:Pic & $29.882^{b, c}$ & $40.771^{b, c}$ & $28.356^{b}$ & $28.308^{b}$ & $31.829 \mathrm{~b}, \mathrm{c}$ \\
\hline DMDS:Pic & $32.431^{b, c}$ & $38.042^{b}$ & $27.654^{a, b}$ & $24.502^{\mathrm{a}}$ & $30.657^{b}$ \\
\hline 1,3-D:Pic & $29.474^{a, b}$ & $39.466^{b, c}$ & $27.187^{a, b}$ & $27.875^{b}$ & $31.000^{b}$ \\
\hline 1,3-D:Pic:Kpam & $33.226^{c}$ & $42.624^{\mathrm{C}}$ & $31.633^{b}$ & $30.071^{b}$ & $34.388^{c}$ \\
\hline
\end{tabular}

Note: means followed by the same letter are not significantly different based on Tukey's adjusted mean comparisons at $p<0.05$.

\subsection{Model Estimation Results}

Equation (1) was estimated with maximum likelihood estimation, while Equation (2) was estimated with the ordinary least squares method. Parameter estimates for the nutsedge model are presented in Table 3, and effects of all fumigants are presented in Table 4. All parameter estimates of fumigant dummy variables are statistically significant, suggesting that applying fumigants changes nutsedge shoots compared to non-fumigated control. The magnitude of the effect is dependent on weather conditions. With both weather variables (TAF and RAF) held constant at their sample means, 1,3-D:Pic:Kpam reduced nutsedge shoots the most by 7.282 shoots $/ \mathrm{m}^{2}$, followed closely by MBr:Pic with 6.964 shoots $/ \mathrm{m}^{2}$ (Table 4). 1,3-D:Pic is the least effective and only reduced 4.159 shoots relative to the non-fumigated. As expected, most interaction terms of fumigants with weather factors are significant. Our results suggest that the increased soil temperature significantly reduced the efficacy and increases nutsedge shoots in tomato production. MBr:Pic is the least affected, confirming its consistency, while 1,3-D:Pic is affected most, resulting in 3 more shoots $/ \mathrm{m}^{2}$ by one increased degree of soil temperature (Table 4 ). To maximize fumigant activity, soil temperatures should be at a minimum of $50{ }^{\circ} \mathrm{F}$. As soil temperature increases, the rate of fumigant conversion to the gas state increases. High soil temperature speeds the gaseous diffusion, thus shortening the exposure time of nutsedge tubers and resulting in lower efficacy. Rainfall also reduced fumigant efficacy, and its effect is significant for 1,3-D:Pic and 1,3-D:Pic:Kpam. An increase of $2.54 \mathrm{~cm}$ (one inch) results in an increased nutsedge density of 0.946 and $0.198 / \mathrm{m}^{2}$ for 1,3-D:Pic and 1,3-D:Pic:Kpam treatments, respectively. It is possible that water hindered fumigant movement and reduced pest control [14]. 
Table 3. Estimation results for nutsedge and grass models.

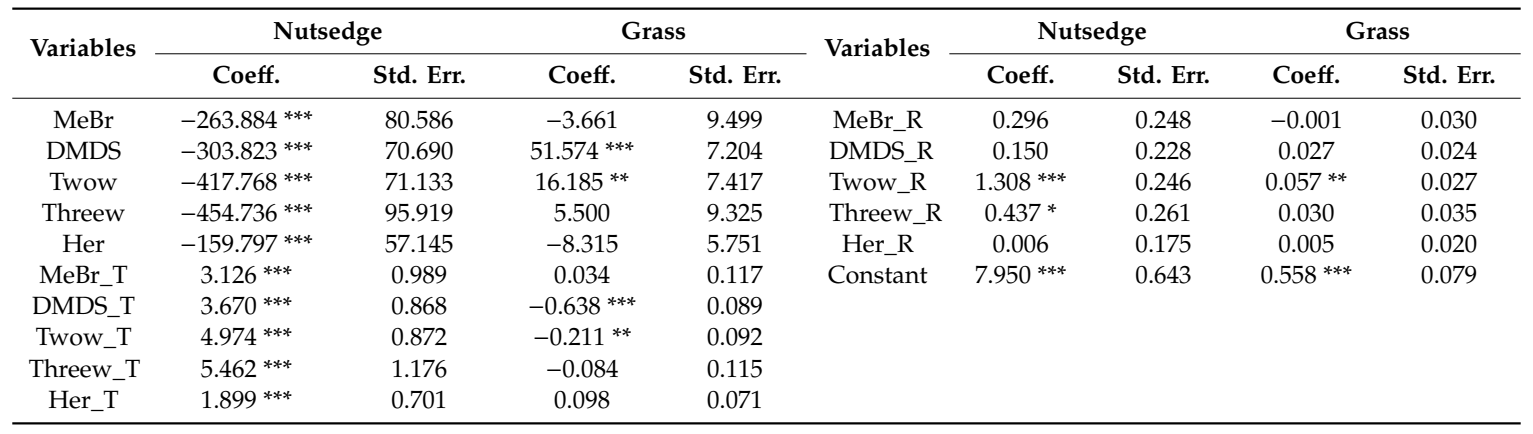

Note: MBr is MBr:Pic, DMDS is DMDS:Pic, Twow is 1,3-D:Pic, Threew is 1,3-D:Pic:Kpam, Her is herbicide; the letters " $\mathrm{T}$ " and " $\mathrm{R}$ " indicate soil temperature and rainfall after fumigation, respectively. *,**, and *** indicate significance at $0.1,0.05$, and 0.01 levels.

Table 4. Effects of fumigants on weed population and tomato yield and impacts of weather variables.

\begin{tabular}{ccccc}
\hline Fumigants & MBr:Pic & DMDS:Pic & 1,3-D:Pic & 1,3-D:Pic:Kamp \\
\hline $\mathrm{MW}_{1}$ & -6.964 & -4.531 & -4.159 & -7.282 \\
$\partial \mathrm{MW}_{1} / \partial \mathrm{Z}_{1}$ & 1.510 & 2.554 & 3.597 & 2.472 \\
$\partial \mathrm{MW}_{1} / \partial \mathrm{Z}_{2}$ & - & - & 0.946 & 0.198 \\
$\mathrm{MW}_{2}$ & -0.695 & 0.200 & -0.359 & -0.748 \\
$\partial \mathrm{MW}_{2} / \partial \mathrm{Z}_{1}$ & - & -0.580 & -0.120 & - \\
$\partial \mathrm{MW}_{2} / \partial \mathrm{Z}_{2}$ & - & - & 0.032 & - \\
$\mathrm{MY}$ & 7.599 & 6.318 & 6.108 & 10.537 \\
$\mathrm{MY} / \partial \mathrm{Z}_{1}$ & -0.493 & -0.023 & -1.007 & -0.807 \\
$\mathrm{MY} / \partial \mathrm{Z}_{2}$ & - & - & -0.141 & -0.065 \\
\hline
\end{tabular}

Note: $Z_{1}, Z_{2}$ are soil temperature and rainfall after fumigation (TAF and RAT); $M_{1}$ is the marginal effect of fumigants on nutesdge control, $\mathrm{MW}_{2}$ is the marginal effect of fumigants on grass control, $\mathrm{MY}$ is the marginal effect of fumigants on tomato yield. Only statistically significant effects are reported.

The estimates for grass shoots were slightly different. First, 1,3-D:Pic:Kpam led the grass reduction with 0.748 shoots $/ \mathrm{m}^{2}$, followed by MBr:Pic (0.695). DMDS:Pic resulted in higher numbers of grass shoots relative to the non-fumigated control. Second, few coefficient estimates of interaction terms are statistically significant, suggesting the efficacy of fumigants in controlling grass shoots are less affected by weather. Third, in contrast to nutsedge, increasing soil temperature reduces grass shoots for both DMDS:Pic and 1,3-D:Pic treatments. Finally, more rainfall increased grass shoots for the 1,3-D:Pic treatment.

Estimation results for the tomato yield equation are presented in Table 5. Most estimates of variables in the equation are statistically significant and have expected signs. Positive estimates of fumigant dummy variables imply that applying fumigants would cause a yield increase compared to the non-fumigated control. Among them, 1,3-D:Pic:Kpam contributes most to the yield increase. The coefficient estimate of soil temperature after transplanting (TAT) is positive and significant, consistent with Adams et al. [15] who found that high temperatures increase fruit absolute volume growth rates. The effect of rainfall after transplanting (RAT) on yield is small and insignificant, which is likely associated with the fact that tomato production in the experiment used drip irrigation. Finally, more nutsedge and grass shoots result in lower yield. Increasing nutsedge by $1 \mathrm{shoot} / \mathrm{m}^{2}$ will lead to a decrease in tomato yield of 0.327 tons/ha, while the effect of an increase of 1 grass shoot $/ \mathrm{m}^{2}$ causes a decrease of 1.398 tons/ha. 
Table 5. Estimation results for tomato yield model.

\begin{tabular}{cccccc}
\hline Variables & Coeff. & Std. Err. & Variables & Coeff. & Std. Err. \\
\hline MBr:Pic & $4.353^{* * *}$ & 1.070 & TAT & $3.604^{* * *}$ & 0.371 \\
DMDS:Pic & $5.118^{* * *}$ & 1.035 & RAT & -0.519 & 0.332 \\
1,3-D:Pic & $4.248^{* * *}$ & 1.022 & Nutsedge & $-0.327^{* * *}$ & 0.061 \\
1,3-D:Pic:Kpam & $7.113^{* * *}$ & 1.074 & Grass & $-1.398^{* *}$ & 0.626 \\
Constant & $-232.060^{* * *}$ & 25.906 & & & \\
\hline \multicolumn{7}{c}{ Note: ${ }^{* *}$ and ${ }^{* * *}$ indicate significance at 0.05 and 0.01 levels, respectively. }
\end{tabular}

The aggregated yield effects of fumigants are shown in Table 4. 1,3-D:Pic:Kpam is the leading fumigant in increasing tomato yield, with 10.537 tons/ha. However, the efficacy varies with weather conditions after fumigation (TAF and RAF). One degree increase in soil temperature can reduce tomato yield by 0.807 tons/ha while one additional inch of rainfall would reduce yield by 0.065 tons/ha due to lower weed control (Table 4). The second largest yield increase is from MBr:Pic, with 7.599 tons/ha. It is responsive only to soil temperature and the magnitude is smaller. The least effective and most unstable fumigant is 1,3-D:Pic.

\subsection{Economic Performance Analysis}

This section presents results of short-term economic performance of fumigants for each season in the trial period as well as the results of simulated, long-term economic performance, taking into account long-term weather variability. The weather conditions in the trial period represent only observed values during that period, which may not adequately capture weather variability over a longer period of time. This issue will be addressed in a simulation under long-term weather variability. Section 3.3.1 compares treatments' mean profits, and Section 3.3.2 ranks treatments in terms of the measure of utility, which accounts for both mean profits and variation of profits (or treatment effects) under long-term weather variability.

\subsubsection{Whole Farm Budgeting Analysis}

Whole farm budgeting considers the financial feature of business performance (e.g., profit) after treatment [16]. Besides the costs of fumigation, harvesting and marketing, it also accounts for other expenses, which are unchanged across treatments, including fertilizers, transplants, and other costs (including fixed costs). Combining the total revenue with total cost information, the average net profit per acre of each treatment is estimated.

First, fumigation costs were calculated, including material, machinery, and labor costs. The market prices of Pic, DMDS, 1,3-D and Kpam and their usage amounts were used to calculate material costs. As with $\mathrm{MBr}$, the original price of $\mathrm{MBr}$, before the ban in 1997, was used and adjusted up for inflation over the years. This calculation represents a hypothetical case if methyl bromide had not been banned, to have a fair comparison. For all four seasons, fumigant prices were adjusted with the Producer Price Index (PPI) and used the average prices over the four seasons to calculate material costs. Fumigation machinery costs included fuel costs, depreciation, and other noncash overhead while labor costs were calculated based on the farm labor rate and working hours of fumigation on an average farm. Two-way and three-way fumigation treatments involve applying fumigants twice with machines and correspondingly, incur double labor and machinery costs. In sum, 1,3-D:Pic:Kpam fumigation cost is the highest at $\$ 3480 /$ ha, followed by DMDS:Pic with the expense of $\$ 3033 / \mathrm{ha}$. MBr:Pic is the least expensive fumigation treatment. Second, harvest and marketing costs, which are in direct proportion to tomato yield, include picking, packing, and hauling costs, container cost, selling cost and organization fee. Similarly, costs for four seasons were adjusted for inflation using the PPI data. Third, other cost categories, which are fixed across treatments, were from production budgets for tomatoes in Southwest Florida [17]. Finally, the revenue was estimated using tomato market prices and yields. The price was an average of January and February prices at the Florida shipping point over the four seasons. 
Net profits of each treatment over the years are presented in Table 6. The results show that, except in 2009, most treatments had negative net profits. This finding is consistent with the reality that the industry is struggling due to both production and market challenges such as the rapidly growing imports from Mexico [18]. The net profits in 2008 for DMDS:Pic and 1,3-D:Pic:Kpam were positive while those of all other treatments were negative. However, the difference was not statistically significant, suggesting that no treatment performs economically better than others. In 2009, all treatments produced positive net profits. MBr:Pic, 1,3-D:Pic, and 1,3-D:Pic:Kpam worked equally well and generated higher net profits than other treatments. All fumigant treatments resulted in losses in 2010 and worked equally well and outperformed the non-fumigated. The same trend was observed in 2011. It can be concluded that, unlike the results for weed control and yield, 1,3-D:Pic:Kpam and 1,3-D:Pic performed as well as MBr:Pic in some years. However, they also performed as poorly as the non-fumigated control for other years. The variation in weather conditions affects fumigation efficacy and increases the variability of their economic performance.

Table 6. Net profits of treatments through the whole farm budgeting method (\$/ha).

\begin{tabular}{ccccc}
\hline Treatments & $\mathbf{2 0 0 8}$ & $\mathbf{2 0 0 9}$ & $\mathbf{2 0 1 0}$ & $\mathbf{2 0 1 1}$ \\
\hline Control & -1634 & $2252^{\mathrm{a}}$ & $-4559^{\mathrm{a}}$ & $-6091^{\mathrm{a}}$ \\
MBr:Pic & -297 & $9661^{\mathrm{b}}$ & $-1693^{\mathrm{a}, \mathrm{b}}$ & $-1737^{\mathrm{b}}$ \\
DMDS:Pic & 1120 & $6252^{\mathrm{c}}$ & $-3247^{\mathrm{a}, \mathrm{b}}$ & $-6130^{\mathrm{a}}$ \\
1,3-D:Pic & -748 & $8390^{\mathrm{b}, \mathrm{c}}$ & $-2840^{\mathrm{a}, \mathrm{b}}$ & $-2211^{\mathrm{b}}$ \\
1,3-D:Pic:Kpam & 1400 & $9995^{\mathrm{b}}$ & $-56^{\mathrm{b}}$ & $-1485^{\mathrm{b}}$ \\
\hline
\end{tabular}

Note: means followed by the same letter are not significantly different based on Tukey's adjusted mean comparisons at $p<0.05$.

\subsubsection{Expected Utility Simulation Analysis}

Means comparison method, discussed in the last subsection, was not able to provide an unambiguous ranking for all treatments, due in part to the high variability around the treatment means. The expected utility method was used, which incorporates risk factors to explicitly account for the variation of net profits of treatments. Specifically, the power utility function, which is the most widely used utility function in empirical analysis [11], was used to evaluate the treatment under a certain weather condition, that is,

$$
U\left(W_{t}\right)=\frac{W_{t}^{1-r}-1}{1-r}
$$

where $W_{t}$ is the grower's end-of-season wealth, which is the grower's initial wealth $\left(W_{0}\right)$ plus random farm profit from a fumigation treatment, i.e., $W_{t}=W_{0}+P_{t} . r$ is the grower risk-aversion coefficient. $r$ ranges from 1 to 3, representing "normal risk aversion" to "high risk aversion" [19]. When $r=1$, the power utility function is degenerated to the logarithmic utility function $\ln \left(W_{t}\right)$. Utility $U\left(W_{t}\right)$ is random because yield (hence farm profit) follows a random distribution. The grower is assumed to choose the treatment that brings him the highest expected (or mean) utility $E\left[U\left(W_{t}\right)\right]=E\left(\frac{\left(W_{0}+P_{t}\right)^{1-r}-1}{1-r}\right)$. The expected utility under $N$ sets of profit under a specific weather scenario $t$ is:

$$
E\left[U\left(W_{t i}\right)\right]=\frac{1}{N} \sum_{i=1}^{N} \frac{\left(W_{0}+P_{t i}\right)^{1-r}-1}{1-r}
$$

where $\mathrm{E}(\cdot)$ is the expectation operator. Following Cao et al. [11], an average tomato grower in Florida is assumed to have 28 ha land and $\$ 3,420,056$ farm equity $\left(W_{0}\right)$.

The first step is to calculate the average expected utility of fumigation treatments with $r=2$ under weather conditions during the trial period (2008-2011), which will demonstrate treatment ranking with limited weather variability observed over 2008-2011. The calculation of the expected utility uses the observed data points for each treatment, which is used to compare the performance of fumigants. Then, 
the expected utility under $T$ sets of simulated weather scenarios is further calculated. The farm profit from each treatment based on Equations (1) and (2) is simulated assuming herbicides are used together with fumigants. The simulation procedure is detailed in Appendix A. Each simulation generates a risky outcome of yield, profit, and utility. The expected utility of $N$ replicates under a specific weather scenario $t$ could be calculated with Equation (8). The weather scenario is further allowed to change (by taking different random values of temperature and rainfall from a weather distribution) and repeat the simulation in Equation (8) to compute the expected utility under diverse weather scenarios.

The expected utilities of observed trials (under observed weather scenarios in the trial period) and simulated values with long-term weather variability are presented in Table 7 . The first column shows the expected utility of the trials over 2008-2011. The ranking results illustrate that the most effective treatment over the trial period is 1,3-D:Pic:Kpam, followed by MBr:Pic and the industry standard, 1,3-D:Pic. DMDS:Pic was the poorest fumigant. However, the ranking changed when accounting for long-term weather variability. First, MBr:Pic outperformed 1,3-D:Pic:Kpam, showing the consistency of MBr:Pic efficacy under diverse weather conditions. Nevertheless, 1,3-D:Pic:Kpam produced a utility closest to MBr:Pic, making it the best alternative to MBr. Second, the industry standard, 1,3-D:Pic, is now worse than DMDS:Pic. Although 1,3-D:Pic generated higher yields than DMDS:Pic, its yield variation is larger across years, making it less stable under diverse weather conditions, thus resulting in a lower utility ranking.

Table 7. Expected utility under different scenarios.

\begin{tabular}{ccccc}
\hline \multirow{2}{*}{ Treatments } & $\begin{array}{c}\text { Trial Period (Observed } \\
\text { Weather Variability) } \boldsymbol{r = 2}\end{array}$ & \multicolumn{2}{c}{ Simulated Weather Scenarios (Long-Term Weather Variability) } \\
\cline { 3 - 5 } & & $\boldsymbol{r}=2$ & $\boldsymbol{r}=1$ & $\boldsymbol{r}=3$ \\
\hline Control & 0.70075 & 0.70846 & 1.23615 & 0.45723 \\
MBr:Pic & 0.71025 & 0.71384 & 1.25564 & 0.45871 \\
DMDS:Pic & 0.70525 & 0.70914 & 1.23912 & 0.45737 \\
1,3-D:Pic & 0.70975 & 0.70906 & 1.23863 & 0.45736 \\
1,3-D:Pic:Kpam & 0.71275 & 0.71377 & 1.25561 & 0.45867 \\
\hline
\end{tabular}

In the computation of expected utility, the farmer's risk attitude (or degree of risk aversion) is assumed to be represented by $r=2$. Yet, the magnitude of risk penalty varies with farmers' risk attitude. In order to investigate the robustness of our findings with respect to risk attitude, the total expected utility was re-calculated with two additional risk aversion levels, $r=1$ and $r=3$, respectively. The corresponding results with different risk aversion levels, reported in the last two columns in Table 7 , show that utility increases when growers are less risk averse $(r=1)$ and decreases when they become more risk averse $(r=3)$, but the rankings are unaffected.

\section{Conclusions and Discussion}

MBr phase-out has caused broad technological shocks [11], which, together with intense competition from Mexico [18,20-22] and labor shortages [23-25], has significantly impacted the U.S. tomato industry. Several alternative fumigants have reached the market which include Pic, DMDS, 1,3-D and Kpam. Although most small fruit and vegetable growers in Florida have settled on them as alternatives to $\mathrm{MBr}$, their reliability in terms of pest management and crop yield is questionable, given that all of the $\mathrm{MBr}$ alternatives are more prone to adverse weather conditions. This study presents an economic analysis of the fumigants' efficacy under variable weather conditions. Regression models were specified and estimated with data from trials over 2008-2011 to identify the effects of weather conditions on fumigants' efficacy in weed control and tomato yield. Although the trials were conducted years ago, these trialed fumigants are still extensively used in the industry. The results show strong empirical evidence of soil temperature and rainfall influencing fumigation efficacy. First, high soil temperature reduces fumigation efficacy in controlling nutsedge while increasing efficacy in controlling grass. 1,3-D:Pic was most affected in terms of efficacy on nutsedge by soil temperature because two important isomers in 1,3-D accelerate their diffusion and are released to the atmosphere 
with increasing temperature [26]. It has also raised a concern about air pollution because a significant proportion of 1,3-D finds its way into the atmosphere during application [26]. Second, rainfall also reduces fumigant efficacy, and its effect is significant for 1,3-D:Pic and 1,3-D:Pic:Kpam. Rainfall leads to the establishment of a water barrier to diffusion of 1,3-D, resulting in the reduced efficacy [27]. Fumigants are volatile compound; ideal weather conditions are needed to achieve the optimal speed of diffusion and application technology can modify this effect [28]. Third, the sensitivity of fumigant efficacy to weather conditions is different across fumigants. MBr:Pic is the least affected by weather conditions and tends to provide consistent pest control, while alternative fumigants are prone to having inconsistent performance under different weather conditions. This finding is in agreement with prior experiments conducted to identify effective alternatives, which often suggest that methyl bromide is the only single treatment that provides consistent weed control $[29,30]$.

Given the inconsistency of fumigants' efficacy under different weather conditions, it is important to take into account weather uncertainty when evaluating the economic performance of fumigants. The study further simulated yields under various weather scenarios. Monte Carlo simulation in the expected utility model was used to allow risk or variability of effects to be penalized in the analysis. Fumigant ranking was found to be significantly different when accounting for weather variability. MBr:Pic performed the best, while 1,3-D:Pic:Kpam was the closest alternative to MBr. Namely, the combination of MBr:Pic is still the most risk-efficient fumigant for Florida tomato production, while the three-way system (1,3-D:Pic:Kpam) is the best among MBr alternatives. In addition, the current industry standard, 1,3-D:Pic, was least effective among fumigants studied due to its inconsistency, raising concerns about the industry choice. However, some previous reports have indicated that 1,3-D:Pic are among the most promising preplant chemical alternatives to $\operatorname{MBr}[31,32]$. This discrepancy highlights the critical importance of accounting for weather variability in fumigant performance evaluation, which also presents a challenging request for scientists to implement much longer trials.

The results of this study illustrate the variability of fumigants' efficacy and the importance of achieving consistent efficacy to identify long-standing and sustainable fumigant alternatives. Scientists have been called to address and remediate weather factors causing significant performance inconsistency. Various fumigation application technology, injection depth, mulch type, and application sites and others have been attempted to improve the consistency. This study fills a knowledge gap by quantifying the effect of weather conditions on fumigation efficacy. Together, the regression model and the expected utility model, along with the simulation techniques, form a useful tool that can be applied across regions or crops.

Author Contributions: Conceptualization, F.W., B.Q. and Z.G.; methodology, F.W., B.Q. and Z.G.; formal analysis, F.W., B.Q. and Z.G.; data curation, A.M. and T.J.; writing-original draft preparation, F.W.; writing-review and editing, F.G., Z.G., N.S.B. and G.E.V.; funding acquisition, Z.G., N.S.B. and G.E.V. All authors have read and agreed to the published version of the manuscript.

Funding: This research was supported by the USDA National Institute of Food and Agriculture [NIFA grant number 2014-51102-22273]. The authors gratefully acknowledge NIFA for the funding provided.

Conflicts of Interest: The authors declare no conflict of interest.

\section{Appendix A. Simulation Procedure of Weather Impact}

To simulate weather impact on treatment effect, weather conditions are allowed to vary with $T$ sets of weather scenarios. Under each set of weather scenario, $N$ sets of replications are simulated. The expected utility is calculated from the sample mean on a given set of profits $(N \times T)$, that is,

$$
\frac{1}{T} \sum_{t=1}^{T} E\left[U\left(W_{t i}\right)\right]=\frac{1}{T} \sum_{t=1}^{T}\left(\frac{1}{N} \sum_{i=1}^{N} \frac{\left(W_{0}+P_{t i}\right)^{1-r}-1}{1-r}\right)
$$

where $P_{t i}$ is the net profit of each treatment at replicate $i$ in the $t$-th weather scenario (or season). The expected utility of each treatment is then ranked to determine the performance of fumigants. 
Random variables include random shocks in weeds and yields $\left(u_{1}, u_{2}, \varepsilon\right)$, as well as random weather variables (TAF, RAF, TAT, and RAT). The vector of weed shocks $\left(u_{1} u_{2}\right)$ in Equation $(1)$ is assumed to be normally distributed with mean zero and variance-covariance matrix estimated in Equation (1). The yield shock $\varepsilon$ is assumed to be a zero-mean normally distributed random variable with estimated variance in Equation (2). Random weather variables (TAF, RAF, TAT, and RAT) are assumed to have a multivariate lognormal distribution, accounting for the covariance between variables, and the levels of uncertainty (variance and covariance) of weather variables employed for the simulation are representative of historical weather risks over 1998-2015 in Florida. Based on the above calibration, the estimated models (Equations (1) and (2)) are used to simulate weed and yield. First, one set of weather values are randomly drawn from the above estimated lognormal distribution. Under such predetermined weather condition, shocks to weed populations $\left(u_{1}\right.$ and $\left.u_{2}\right)$ are randomly drawn 300 times $(\mathrm{N}=300)$ from their respective distributions and placed into Equation (1) to generate 300 weed values for each weed (nutsedge and grass). Based on Equation (1), if the value is negative, the forecast shoot is zero; when it is positive, the forecast shoot is the value itself. Second, yield shocks $(\varepsilon)$ are randomly drawn 300 times from its respective distribution and placed together with shoot forecasts into Equation (2) to generate 300 yields. The net profit corresponding to each yield is calculated based on tomato market prices and production costs. The procedure is replicated again when a new $(t$-th) set of weather values is drawn. To allow for enough variability of weather, 100 weather scenarios are drawn $(T=100)$. These 100 sets of weather scenarios and 300 sets of profit under each weather scenario are used to calculate the expected utility with Equation (A1) for each treatment. In total, 30,000 data points are simulated for each treatment. The treatment with the highest total expected utility values represents the best performance under weather uncertainty. To generate realistic weather scenarios and avoid extreme weather values, the upper and lower bound was set for weather variables and only considered those drawn values within the upper and lower bounds, which are set at $30 \%$ higher and lower than the historical highest and lowest values observed over 1998-2015. The bounds cover approximately $99 \%$ of the assumed distribution.

\section{References}

1. Gilreath, J.P.; Santos, B.M.; Gilreath, P.R.; Jonesa, J.P.; Noling, J.W. Efficacy of 1,3-dichloropropene plus chloropicrin application methods in combination with Pebulate napropamide in tomato. Crop Prot. 2004, 23, 1187-1191. [CrossRef]

2. Gilreath, J.P.; Santos, B.M. Methyl bromide alternatives for weed soilborne disease management in tomato (Lycopersicon esculentum). Crop Prot. 2004, 23, 1193-1198. [CrossRef]

3. Gilreath, J.P.; Santos, B.M. Efficacy of 1,3-Dichloropropene plus Chloropicrin in combination with herbicides on purple nutsedge (Cyperus rotundus) control in tomato. Weed Technol. 2005, 19, 137-140. [CrossRef]

4. Gilreath, J.P.; Santos, B.M. Purple nutsedge (Cyperus rotundus) control with fumigant pebulate combinations in tomato. Weed Technol. 2005, 19, 575-579. [CrossRef]

5. Gilreath, J.P.; Santos, B.M.; Busacca, J.D.; Eger, J.E., Jr.; Mirusso, J.M.; Gilreath, P.R. Validating broadcast application of Telone C-35 complemented with chloropicrin herbicides in commercial tomato farms. Crop Prot. 2006, 25, 79-82. [CrossRef]

6. Freeman, J.H.; McAvoy, E.J.; Boyd, N.S.; Dittmar, P.J.; Ozores-Hampton, M.; Smith, H.A.; Vallad, G.E.; Webb, S.E. Tomato production. In Vegetable Production Hand Book of Florida 2015-2016; Dittmar, P.J., Freeman, J.H., Vallad, G.E., Eds.; University of Florida Institute of Food and Agricultural Sciences: Gainesville, FL, USA, 2016; pp. 211-234.

7. Hanson, B.D.; Shrestha, A. Weed control with methyl bromide alternatives. CAB Rev. Perspect. Agric. Vet. Sci. Nutr. Nat. Resour. 2006, 1,1-13. [CrossRef]

8. Sydorovych, O.; Safley, C.D.; Ferguson, L.M.; Poling, E.B.; Fernez, G.E.; Brannen, P.M.; Monks, D.W.; Louws, F.J. Economic evaluation of methyl bromide alternatives for the production of strawberries in the Southeastern United States. HortTechnology 2006, 16, 118-128. [CrossRef] 
9. Sydorovych, O.; Safley, C.D.; Welker, R.M.; Ferguson, L.M.; Monks, D.W.; Jennings, K.; Driver, J.; Louws, F.J. Economic evaluation of methyl bromide alternatives for the production of tomatoes in North Carolina. HortTechnology 2008, 18, 705-713. [CrossRef]

10. Byrd, M.M.; Escalante, C.L.; Fonsah, E.G.; Wetzstein, M.E. Feasible fumigant-herbicide system alternatives to methyl bromide for bell pepper producers. J. Agribus. 2007, 25, 31-45.

11. Cao, X.; Guan, Z.; Vallad, G.E.; Wu, F. Economics of fumigation in tomato production: The impact of methyl bromide phase-out on the Florida tomato industry. Int. Food Agribus. Manag. 2019, 22, 589-600. [CrossRef]

12. Tobin, J. Estimation of relationships for limited dependent variables. Econometrica 1958, 26, 24-36. [CrossRef]

13. Wooldridge, J. Econometric Analysis of Cross Section Panel Data; The MIT Press: London, UK, 2010.

14. MacRae, A.; Noling, J.; Snodgrass, C. Maximizing the Efficacy of Soil Fumigant Applications for Raised-Bed Plasticulture Systems of Florida; EDIS document HS1169; University of Florida: Gainesville, FL, USA, 2010.

15. Adams, S.R.; Cockshull, K.E.; Cave, C.R.J. Effect of temperature on the growth and development of tomato fruits. Ann. Bot. 2001, 88, 869-877. [CrossRef]

16. Riggs, W.W.; Curtis, K.R.; Harris, T.R. Importance and Use of Enterprise Budgets in Agricultural Operations; University of Nevada Cooperative Extension: Reno, NV, USA, 2012; Available online: https//www.unce.unr. edu/publications/files/ag/2005/sp0512.pdf (accessed on 25 July 2019).

17. VanSickle, J.; Smith, S.; McAvoy, E. Production Budget for Tomatoes in Southwest Florida; EDIS Document FE818; University of Florida: Gainesville, FL, USA, 2009.

18. Wu, F.; Guan, Z.; Suh, D.H. The effects of tomato suspension agreements on market price dynamics and farm revenue. Appl. Econ. Perspect. Policy 2018, 40, 316-332. [CrossRef]

19. Anderson, J.; Dillon, J.L. Risk Analysis in Dryland Farming Systems; Food Agricultural Organization of the United Nations: Rome, Italy, 1992.

20. Wu, F.; Guan, Z.; Whitaker, V. Optimizing yield distribution under biological and economic constraints: Florida strawberries as a model for perishable commodities. Agric. Syst. 2015, 141, 113-120. [CrossRef]

21. Suh, D.H.; Guan, Z.; Khachatryan, H. The impact of Mexican competition on the U.S. strawberry industry. Int. Food Agribus. Manag. 2017, 20, 591-604. [CrossRef]

22. Wu, F.; Qushim, B.; Calle, M.; Guan, Z. Government support in Mexican agriculture. Choices 2018, $33,1-11$.

23. Guan, Z.; Wu, F.; Roka, F.; Whidden, A. Agricultural labor and immigration reform. Choices 2015, 30, 1-9.

24. Wu, F.; Guan, Z. Foreign guest workers or domestic workers? Farm labor decisions and implications. Presented at the Agricultural and Applied Economics Association Annual Meeting, Boston, MA, USA, 31 July-2 August 2016.

25. Roka, F.M.; Guan, Z. Farm labor management trends in Florida, USA - challenges and opportunities. Int. J. Agric. Manag. 2018, 7, 1-9.

26. Dungan, R.S.; Gan, J.; Yates, S.R. Effect of temperature, organic amendment rate and moisture content on the degradation of 1,3-dichloropropene in soil. Pest Manag. Sci. 2001, 57, 1107-1113. [CrossRef]

27. Lembright, H.W. Soil fumigation: Principles and application technology. J. Nematol. 1990, 22, 632-644.

28. Wang, D.; Yates, S.R.; Ernst, F.F.; Knuteson, J.A.; Brown, G.E. Volatilization of 1,3-Dichloropropene under different application methods. Water Air Soil Poll. 2001, 127, 109-123. [CrossRef]

29. García-Méndez, E.; García-Sinovas, D.; Becerril, M.; De Cal, A.; Melgarejo, P.; Martínez-Treceño, A.; Fennimore, S.A.; Soria, C.; Medina, J.J.; López-Aranda, J.M. Chemical alternatives to methyl bromide for weed control and runner plant production in strawberry nurseries. HortSicence 2008, 43, 177-182. [CrossRef]

30. García-Méndez, E.; García-Sinovas, D.; Andrade, M.A.; Cal, A.D.; Melgarejo, P.; Salto, T.; Martínez-Beringola, M.L.; Redondo, C.; Martínez-Treceño, A.; Becerril, M.; et al. López-Aranda. Alternatives to Methyl Bromide for Strawberry Nursery Production in Spain. Acta Hortic. 2009, 842, 965-968. [CrossRef]

31. Jones, J.P.; Gilreath, J.P.; Overman, A.J.; Noling, J.W. Overman. Control of soil-borne disease of mulched tomato by fumigation. Proc. Fla. State Hortic. Soc. 1995, 108, 201-203.

32. Locascio, S.J.; Gilreath, J.P.; Dickson, D.W.; Kucharek, T.A.; Jones, J.P.; Noling, J.W. Noling, J.W. Fumigant alternatives to methyl bromide for polyethylene-mulched tomato. HortScience 1997, 32, 1208-1211. [CrossRef]

(C) 2019 by the authors. Licensee MDPI, Basel, Switzerland. This article is an open access article distributed under the terms and conditions of the Creative Commons Attribution (CC BY) license (http://creativecommons.org/licenses/by/4.0/). 